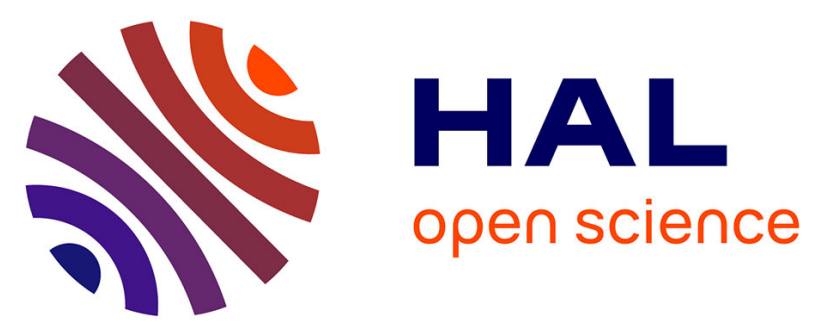

\title{
The activation process ofArabidopsis thaliana A1 gene encoding the translation elongation factor EF-I is conserved among angiosperms
}

Catherine Curie, Thierry Liboz, Marie-Hélène Montané, Dominique Rouan, Monique Axelos, Bernard Lescure

\section{To cite this version:}

Catherine Curie, Thierry Liboz, Marie-Hélène Montané, Dominique Rouan, Monique Axelos, et al.. The activation process ofArabidopsis thaliana A1 gene encoding the translation elongation factor EF-I is conserved among angiosperms. Plant Molecular Biology, 1992, 18, pp.1083-1089. 10.1007/BF00047711 . hal-03081959

\section{HAL Id: hal-03081959 https://hal.science/hal-03081959}

Submitted on 18 Dec 2020

HAL is a multi-disciplinary open access archive for the deposit and dissemination of scientific research documents, whether they are published or not. The documents may come from teaching and research institutions in France or abroad, or from public or private research centers.
L'archive ouverte pluridisciplinaire $\mathbf{H A L}$, est destinée au dépôt et à la diffusion de documents scientifiques de niveau recherche, publiés ou non, émanant des établissements d'enseignement et de recherche français ou étrangers, des laboratoires publics ou privés.

\section{(ㅇ)(1) $\$$}

Distributed under a Creative Commons Attribution - NonCommercial - NoDerivatives $\mid 4.0$ 
Plant Molecular Biology 18: 1083-1089, 1992.

(C) 1992 Kluwer Academic Publishers. Printed in Belgium.

1083

\title{
The activation process of Arabidopsis thaliana Al gene encoding the translation elongation factor EF- $1 \alpha$ is conserved among angiosperms
}

\author{
Catherine Curie ${ }^{1}$, Thierry Liboz ${ }^{1}$, Marie-Hélène Montané ${ }^{2}$, Dominique Rouan ${ }^{1}$, Michèle Axelos ${ }^{1}$ and \\ Bernard Lescure ${ }^{1 *}$ \\ ${ }^{1}$ Laboratoire de Biologie Moléculaire des Relations Plantes-Microorganismes, CNRS-INRA, BP 27, \\ 31326 Castanet-Tolosan Cedex, France (*author for correspondence); ${ }^{2}$ Rhône Poulenc Secteur Agro, 14-20 \\ rue Pierre Baizet, BP 9163, 69263 Lyon Cedex 09, France
}

Received 28 June 1991; accepted in revised form 7 January 1992

Key words: translation elongation factor genes, promoter analysis, evolution

\begin{abstract}
In Arabidopsis thaliana, the activation process of the A1 EF-1 $\alpha$ gene depends on several elements. Using the GUS reporter gene, transient expression experiments have shown that mutations of upstream cisacting elements of the Al promoter, or the deletion of an intron located within the $5^{\prime}$ non-coding region, similarly affect expression in dicot or monocot protoplasts. The results reported here strongly suggest that this $5^{\prime}$ intron is properly spliced in Zea mays. We show that two trans-acting factors, specifically interacting with an upstream activating sequence (the TEF 1 box), are present in nuclear extracts prepared from $A$. thaliana, Brassica rapa, Nicotiana tabacum and $Z$. mays. In addition, a DNA sequence homologous to the TEF 1 box, found at approximately the same location within a Lycopersicon esculentum EF-1 $\alpha$ promoter, interacts with the same trans-acting factors. Homologies found between the $A$. thaliana and $L$. esculentum TEF 1 box sequences have allowed us to define mutations of this upstream element which affect the interaction with the corresponding trans-acting factors. These results support the notion that the activation processes of $A$. thaliana EF- $1 \alpha$ genes have been conserved among angiosperms and provide interesting data on the functional structure of the TEF 1 box.
\end{abstract}

\section{Introduction}

The elongation factor EF-1 $\alpha$ belongs to the housekeeping protein family and has been intensively studied because of its central role in the protein synthesis process [23]. In spite of these studies, except for Saccharomyces cerevisiae [15] and Arabidopsis thaliana [8], there are no published data concerning the characterization of cisand trans-acting elements involved in the activation of EF- $1 \alpha$ genes.
In A. thaliana, EF- $1 \alpha$ is encoded by a small multigenic family of four members (A1-A4) which are all actively transcribed $[1,19]$. Using Arabidopsis protoplasts, transfection experiments have shown that the Al promoter mediates a transient expression higher than that obtained using the cauliflower mosaic virus (CaMV) $35 \mathrm{~S}$ promoter, one of the strongest promoters known both in transient expression systems and stably transformed plant cells [1]. This high level of expression appears to be conserved in transgenic 
Arabidopsis (unpublished data). Deletion analysis of A1 promoter has shown that several elements are involved in the transcription activation process in transfected Arabidopsis cells [8]. The location of these elements within the A1 promoter is indicated in Fig. 1A. A DNA sequence located upstream of position -289 relative to the transcription initiation site is required for a maximum activity. One cis-acting domain, the TEF 1 box, has been accurately mapped $100 \mathrm{bp}$ upstream of transcription initiation site. This domain is the target for trans-acting factors identified in nuclear extracts prepared from Arabidopsis leaves or cell suspension cultures. In addition, we have shown that the $\mathrm{A} 1$ gene contains an intron, located within the $5^{\prime}$ non-coding region. Evidence has been obtained that this intron is essential to the expression of the GUS reporter gene used in the transient expression experiments. [8].

Here, we report results showing that mutations of the A 1 promoter similarly affect the expression in dicot or monocot protoplasts and that factors interacting with the TEF 1 box are present in nuclear extracts prepared from $A$. thaliana, Brassica rapa, Nicotiana tabacum and Zea mays. Moreover, we show that a related DNA sequence found at approximately the same location within the Le EF-1 Lycopersicon esculentum EF-1 $\alpha$ promoter [25], specifically interacts with the same transacting factors. These data have allowed us to define by mutagenesis, two important domains within the TEF 1 box.

\section{Material and methods}

\section{Transient gene expression assays}

The plasmid constructions used to transfect the protoplasts have been already described [8]. The protoplasts were prepared from cell suspension cultures of $A$. thaliana [1] and of $Z$. mays (49S1 embryogenic cell line developed by T. Hardy, Rhône Poulenc Agro), or from N. tabacum leaves [7]. For $A$. thaliana and $N$. tabacum, transfections were performed according to the $\mathrm{Ca}\left(\mathrm{NO}_{3}\right)_{2}-$ PEG procedure [22]. The electroporation method was used for the transfection of Z. mays protoplasts [9]. In all cases, $20 \mu \mathrm{g}$ of plasmid DNA, carrying the indicated promoter configuration fused to the GUS reporter gene, were used to transfect $10^{6}$ protoplasts. The GUS activity was measured after $20 \mathrm{~h}$ by fluorometry [16].

\section{Gel retardation assays}

Crude nuclear extracts were prepared from young leaves of B. rapa, N. tabacum or Z. mays, using the procedure described for the preparation of $A$. thaliana nuclear extracts [8]. Binding assays were done in a volume of $30 \mu \mathrm{l}$ containing $10 \mathrm{mM}$ TRIS- $\mathrm{HCl} \mathrm{pH} 8,50 \mathrm{mM} \mathrm{NaCl}, 7 \mathrm{mM}$ 2-mercaptoethanol, $10 \%$ glycerol, $2 \mu \mathrm{g}$ of poly (dI-dC), $1000-5000 \mathrm{cpm}(0.1-0.5 \mathrm{ng})$ of ${ }^{32} \mathrm{P}$-labelled probe and $2-5 \mu \mathrm{g}$ of nuclear proteins. After $20 \mathrm{~min}$ at $25^{\circ} \mathrm{C}$, the free and bound DNA were separated on $5 \%$ polyacrylamide gels in $0.5 \times$ TBE.

\section{Results}

In order to determine whether the activity of cis elements involved in the activation of the A. thaliana EF-1 $\alpha$ A1 promoter was conserved among angiosperms, characteristic promoter mutations were tested in N. tabacum and Z. mays protoplasts. Figure 1A shows a schematic representation of the $\mathrm{A} 1$ promoter, with the location of the relevant cis elements [8]. The GUS activities given in Fig. 1B are expressed relative to the fulllength promoter ( $\mathrm{x}$-TEF-TATA-IVS configuration: 2300 bp upstream of the AUG translation initiation codon fused to the GUS reporter gene). As in $A$. thaliana, in transfected $Z$. mays protoplasts the full-length $A 1$ promoter appears to drive a GUS activity higher than that obtained using the CaMV 35 S promoter (CaMV 35S configuration). A 5 ' deletion down to the position -111 relative to the transcription initiation site (TEFTATA-IVS configuration), led to about a twofold decrease in the GUS activity. This moderate effect, which depends on a cis-acting element 


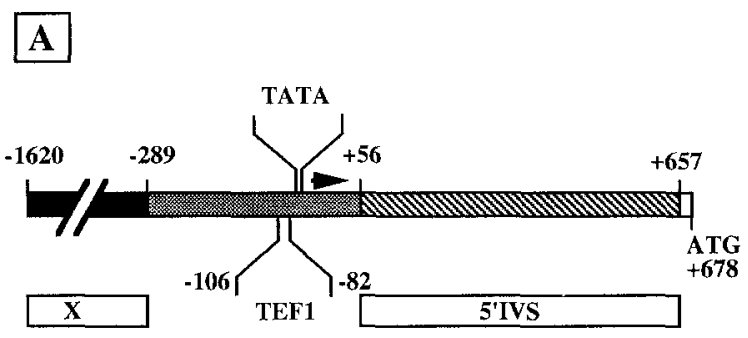

B

\begin{tabular}{|lccc|}
\hline $\begin{array}{l}\text { Promoter } \\
\text { configuration }\end{array}$ & A. thaliana & N. tabacum & Z. mays \\
\hline X-TEF-TATA-IVS & 100 & 100 & 100 \\
TEF-TATA-IVS & $40+/-5$ & $60+/-2$ & $\mathbf{5 1 + / - 8}$ \\
TATA-IVS & $2,5+/-0,2$ & $4+/-1$ & $3+/-2$ \\
TEF-TATA & $3+/-0,2$ & ND & $2+/-1$ \\
CaMV 35S & $42+/-5$ & ND & $21+/-4$ \\
\hline
\end{tabular}

Fig. 1. A. Schematic representation showing the location of EF-1 $\alpha$ A 1 promoter elements involved in the activation of expression [8]. The positions are relative to the transcription initiation site. See the text for details. B. Transient expression in $A$. thaliana, N. tabacum and $Z$. mays protoplasts. The nature of the promoter configuration indicated is detailed in the text. The relative GUS activities, normalized to the full length promoter $(100 \%)$, are the mean of data from at least three independent transfections. After $20 \mathrm{~h}$, the GUS activity measured for the full length promoter was 120,6 or $30 \mathrm{nmol} / \mathrm{min}$ per mg protein for $A$. thaliana, $N$. tabacum or $Z$. mays protoplasts respectively. ND, not determined.

located upstream of the position -289 , appears to be conserved among the three species tested (two dicots and one monocot). Deletion down to the position -100 (TATA-IVS configuration), produced a dramatic drop of GUS activity in $A$. thaliana as in $N$. tabacum and Z. mays. This deletion disrupts an upstream activating sequence (the TEF1 box; see Fig. 1A and 4A) required for expression in Arabidopsis. Therefore, our results suggested that the function of the TEF 1 box was conserved in N. tabacum and Z. mays. To confirm this point, we undertook a search for proteinDNA interactions in the region of the TEF 1 box, using nuclear extracts prepared from various plants. Using Arabidopsis nuclear extracts, we have previously shown that two complexes $(\mathrm{C} 1$ and $\mathrm{C} 2$ ) are formed with a DNA probe extending from position -111 to +46 relative to the

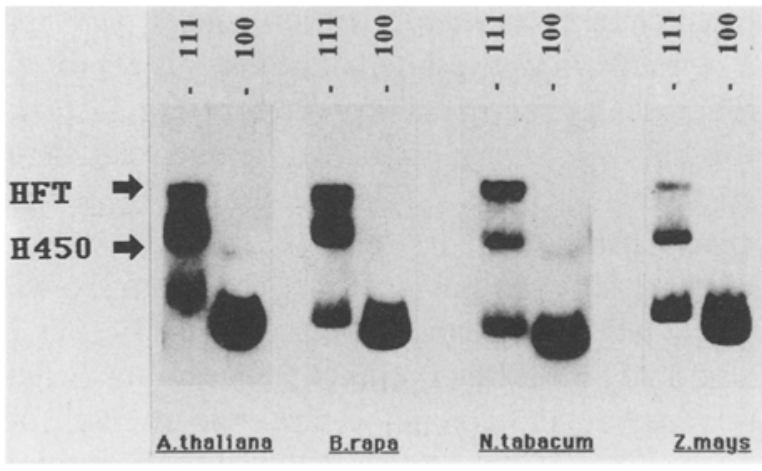

Fig. 2. Identification by gel retardation of trans-acting factors interacting with the TEF1 box. The probes used extend from the $5^{\prime}$ position -100 or -111 to the position +46 relative to the transcription initiation site. The origin of nuclear extracts used is indicated. HFT and H450 correspond to $\mathrm{C} 1$ and $\mathrm{C} 2$ complexes previously described [8] (see the text for details).

transcription initiation site and that these two complexes disappear using a probe deleted down to position -100 [8]. Therefore, the same DNA fragments $(-111 /+46$ and $-100 /+46)$ were used as probes to test for the presence of trans-acting factors specifically interacting with the TEF 1

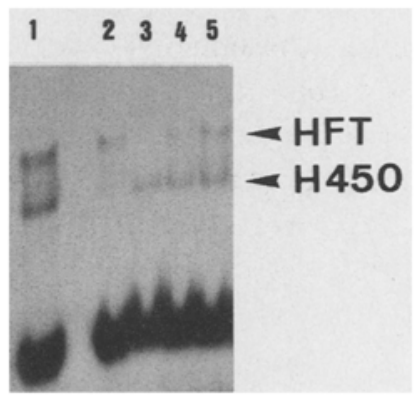

Fig. 3. Fractionation of HFT and H450 on Heparin-Ultrogel. A crude nuclear extract prepared from $Z$. mays was chromatographed on Heparin-Ultrogel. The crude extract was loaded on the column at an ionic strength of $50 \mathrm{mM} \mathrm{NaCl}$ in the nuclear extraction buffer [8]. The elution was done step by step by increasing of $100 \mathrm{mM} \mathrm{NaCl}$ the ionic strength at each step. The binding activity was tested for each fraction by gel retardation assays, using as probe a 50 -mer double-stranded oligonucleotide corresponding to a sequence overlapping the Arabidopsis TEF 1 box (sequence underlined in Fig. 4A). 1 , crude nuclear extract; 2 , flow-through fraction; $3,450 \mathrm{mM}$ $\mathrm{NaCl}$ fraction; 4 and 5 , as in 3 but supplemented by half (4) or the same amount (5) of flow-through fraction proteins used in 2. 
box, in nuclear extracts prepared from $A$. thaliana, $B$. rapa, $N$. tabacum or $Z$. mays. The results of gel retardation experiments reported in Fig. 2 show that, as in Arabidopsis, two complexes were invariably observed with the -111 probe, but absent using the -100 probe. These two DNA binding activities have distinct chromatographic properties on heparine-Sepharose (Fig. 3, lanes 2 and 3 ). Under the experimental conditions used (loading on the column at an ionic strength of $50 \mathrm{mM} \mathrm{NaCl}$ ), the protein involved in the forma- tion of the upper complex $(\mathrm{C} 1)$ is recovered in the flow-through fraction whereas that involved in the formation of the lower complex (C2) is eluted from the column at an ionic strength of $450 \mathrm{mM}$ $\mathrm{NaCl}$. For this reason, the $\mathrm{C} 1$ and $\mathrm{C} 2$ complexes [8] have been renamed HFT (for heparin flow through fraction) and $\mathrm{H} 450$ (for heparin $450 \mathrm{mM}$ $\mathrm{NaCl}$ fraction) respectively. In binding assays, the mixture of HFT and H450 does not reveal cooperative effects in their DNA binding properties (Fig. 3, lanes 4 and 5).

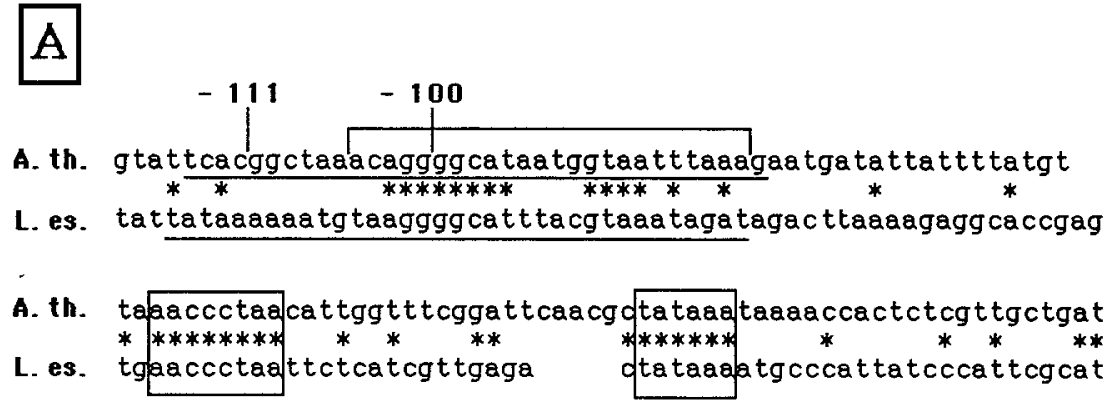

$\begin{array}{llllllll}\text { NS C . } & 0 & 0 & 0 & 0 & + \\ \text { L es C. } & 0 & 0 & 0 & + & 0 \\ \text { A th C. } & 0 & 0 & + & 0 & 0 \\ \text { N ezt. } & 0 & + & + & + & +\end{array}$

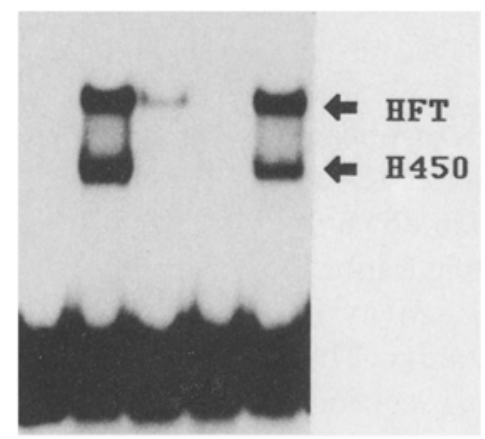

Fig. 4. A. Comparison between the sequences located upstream of the cap site of the EF-1 $\alpha$ A. thaliana Al gene (A. th.) [1] and the corresponding region of the L. esculentum Le gene (L. es.) [25]. Similarities are indicated by asterisks between the sequences. The TATA and the Telo motifs are boxed. The square bracket above the Al sequence represents the protected region of HFT and H450 complexes against OP-Cu cleavage [8]. The A. thaliana or L. esculentum underlined sequences correspond to doublestranded synthetic oligonucleotides used for the gel retardation experiments reported in B. The indicated -111 and -100 positions are relative to the transcription initiation site of $A$. thaliana $\mathrm{A} 1$ gene. B. Gel retardation experiment showing the conservation of the TEF-1 element in L. esculentum. A double-stranded synthetic oligonucleotide corresponding to the $L$. esculentum sequence underlined in A was used as probe. When indicated, the binding reaction was supplemented with 10 ng of competitor (molar excess of competitor: 50). NS C., non-specific competitor corresponding to the double-stranded oligonucleotide 5'-TCGAATTCTATGTTAAACCCTAACATTGATATCGA-3'. L. es C. and A th C., L. esculentum and A. thaliana competitors respectively, corresponding to the sequences underlined in A. N. ext., $2 \mu \mathrm{g}$ of Z. mays nuclear extract. HFT and H450 correspond to $\mathrm{C} 1$ and $\mathrm{C} 2$ complexes previously described [8] (see text for details). 
In plants, in addition to the four $A$. thaliana genes encoding EF- $1 \alpha$, the structure of a $L$. esculentum EF- $1 \alpha$ genomic clone has been recently reported [25]. Figure 4A shows an alignment between sequences located immediately upstream of the cap site of the $A$. thaliana EF- $1 \alpha \mathrm{A} 1$ gene and the corresponding region of the $L$. esculentum EF- $1 \alpha$ gene. Upstream of a putative TATA box of the L. esculentum promoter, two blocks of homologies were found with the Arabidopsis A1 promoter. The first one concerns a strikingly conserved sequence, the telo box, homologous to the repeat motif of higher eukaryote telomeres and found at the same location within the four A. thaliana EF-1 $\alpha$ promoters [1]. The second one is homologous to the TEF 1 box. This observation prompted us to test the ability of the L.esculentum TEF 1-box like sequence to interact with the HFT and H450 proteins. Figure $4 \mathrm{~B}$ shows the results of a gel retardation experiment conducted using $Z$. mays nuclear extracts and a labelled probe consisting of a double-stranded synthetic oligonucleotide containing the TEF 1like sequence of L.esculentum. This synthetic probe was able to form retarded complexes which were competed by $A$. thaliana or L. esculentum TEF 1 unlabelled sequences. In contrast, an unrelated double-stranded oligonucleotide corresponding to $\mathrm{A} 1$ promoter sequences extending from positions -70 to -45 relative to the transcription initiation site (see Fig. 4a), did not prevent the formation of these complexes. These data clearly show that the HFT and H450 proteins specifically interact with the putative TEF 1 box of $L$. esculentum. Moreover, they suggest that the sequence AGGGGCATNNNNGTAANTNNA (Fig. 4A) is a basic motif required for the recognition of the TEF 1 box by these proteins. In order to confirm this assumption, two mutated TEF 1 boxes derived from the Arabidopsis TEF 1 box (Fig. 4A, upper line), have been used as probe in binding assays using A. thaliana nuclear extracts. In the first mutation ( $\mathrm{mt} 1$ probe), within a 50-mer double-stranded oligonucleotide corresponding to sequences overlapping the TEF 1 box (wt probe), the sequence ... AGGGGCAT... has been replaced with ...
In the second one ( $\mathrm{mt} 2$ probe), the sequence ...GGTAA ... has been replaced with ... $\underline{\text { GAGCA }}$... The results of gel retardation experiments reported in figure 5 show that the $\mathrm{mt} 1$ mutation, as the $\mathrm{mt} 2$ mutation, affect the interaction of HFT and H450 proteins with the TEF 1 box, showing the functional importance of conserved sequences AGGGGCAT and GTAA within the TEF 1 box.

In addition to the two upstream elements mentioned above (the $x$ element and the TEF-1 box), we have already shown that an intron located within the $5^{\prime}$ non-coding region of A1 gene was essential to obtain a maximum expression in A. thaliana protoplasts [8]. The results reported in Fig. 1B show that the role of this $5^{\prime}$ intron in the activation of the expression is conserved in a monocot. A chimaeric construct, obtained by substitution of genomic sequences located upstream of the AUG translation initiation codon by their corresponding cDNA sequences (TEFTATA configuration), led to a 20 -fold lower GUS activity in $Z$. mays protoplasts compared to that obtained using the TEF-TATA-IVS promoter configuration.

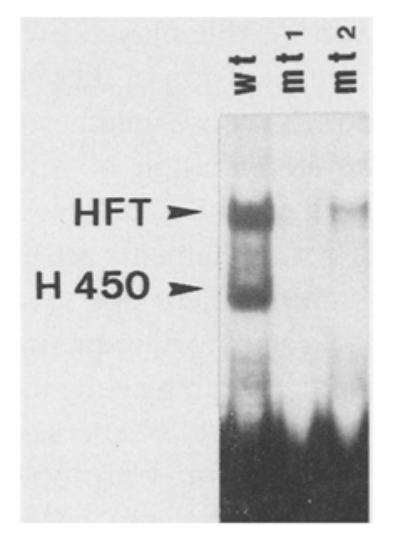

Fig. 5. Gel retardation assays showing the effect of TEF 1 box mutations on the formation of HFT and H450 complexes. wt probe: synthetic double-stranded oligonucleotide probe, 5' -gggtctagaGGCTAAACAGGGGCATAATGGTAATTTAAAGAATcgatggg- $3^{\prime}$, corresponding to the Arabidopsis DNA sequence overlapping the TEF 1 box (see Fig. 4A); $m$ t I probe: 5'-gggtctagaGGCTAAACAGaaaCATAATGGTAATTTAAAGAATcgatggg-3'; $m t 2$ probe: 5'-gggtctagaGGCTAAACAGGGGCATAATGgtaATTTAAAGAATcgatggg-3' . 


\section{Discussion}

In the majority of cases where genes have been transferred into heterologous plants, qualitative aspects of expression are maintained. However, this conservation appears to depend on the evolutionary distance between donor and host plants. Thus, monocot-dicot transfers often result in no or inappropriate expression of the transferred gene [see 28 and references therein]. The data reported in this paper show that cis- and transacting elements involved in the transcription activation of the Arabidopsis EF-1 $\alpha$ A1 gene are conserved among angiosperms.

The results obtained in $Z$. mays are interesting in several respects. They show that in a monocot, the Al promoter is about four fold more efficient than the CaMV $35 \mathrm{~S}$ promoter and that this expression depends on the same $c i s$-acting elements as those required for expression in $A$. thaliana. As in Arabidopsis, the intron which interrupts the $5^{\prime}$ untranslated A1 RNA leader is essential to obtain an optimum GUS activity. It must be noted that such $5^{\prime}$ IVS have been found in all the higher eukaryotic EF-1 $\alpha$ genes characterized up to now $[14,18,25,27]$. The conservation during the evolution of this structural organization probably reflects an important role played by these $5^{\prime}$ IVS in the control of expression of these genes. At the moment, we do not know whether this intron is involved in the stabilization of mRNA precursors, as suggested for the $Z$. mays Adh1 intron 1 [5], whether cis-acting elements are present within the $5^{\prime}$ IVS, or both. There are several cases in animals in which regulatory sequences have been localized within intervening sequences [ e.g. 4, 6, 24]. The high level of GUS expression driven by the Al promoter in $Z$. mays protoplasts strongly suggests that the intron located within the $5^{\prime}$ noncoding region is properly spliced. Several AUG codons, in frame with the GUS reporter gene, are present within this intron. All of them are followed by stop codons, excluding that in Z. mays, alternative translation initiations could occur from these AUG codons on mRNA precursors. These data contrast with the assumption that the fidelity with which processing signals of heterol- ogous RNA are recognized in monocots and dicots can vary considerably [17]. However, it must be noted that this assumption results from experiments where monocot genes have been transferred in dicots. From considerations of the much higher $\mathrm{G}+\mathrm{C}$ content of introns in monocots than dicots, and the possible consequences of this base composition on the secondary structures of mRNA precursors, it has been suggested and shown that most of the primary transcripts from dicot genes could be efficiently spliced in monocots, but not the contrary $[3,11]$.

In all plants analysed, we have shown that at least two nuclear factors interacted with the A. thaliana TEF 1 box and that the same factors bound a putative TEF 1 box from a $L$. esculentum EF- $1 \alpha$ promoter. Many plant DNA binding proteins which interact with promoter elements of diverse genes have now been characterized [see 13 and references therein]. The comparison between the consensus target sequences for these DNA-binding proteins and the TEF 1 box does not reveal striking homologies. The sequence AGGGGCAT found within the $5^{\prime}$ part of the TEF 1 box of $A$. thaliana and $L$. esculentum shares some resemblance to the evolutionarily conserved G box ACGTGGCAPy recognized by the nuclear factor GBF [10]. Similarly, the conserved GTAA motif of the $3^{\prime}$ part of the TEF 1 box is also found within the ocs element of T-DNA and plant viral promoters and within the box $\mathrm{II}^{*}$ of pea rbcS promoters $[2,12,26]$.

The presence of the two DNA binding activities HFT and H450 in all the plants examined so far, together with their distinct chromatographic properties, suggest the presence of two different proteins which could combine their effect in an exclusive manner by interacting with overlapping sequences. Such an exclusion mechanism has been already described in yeast and in animals (e.g. 20, 21]. The two TEF 1 box mutations tested in this work, similarly affect the interaction with the HFT and H450 proteins (Fig. 5), suggesting that the sequences required for the formation of HFT and H450 complexes are identical or overlap. A collection of TEF 1 box point mutations is required to test whether the overlapping se- 
quences involved in the formation of HFT and H450 complexes are identical or not, and to study the role of each one of these two complexes in the activation or in the repression of the expression process of EF- $1 \alpha$ genes.

\section{References}

1. Axelos M, Bardet C, Liboz T, Le Van Thai A, Curie C, Lescure B: The gene family encoding the Arabidopsis thaliana translation elongation factor EF-1 $\alpha$ : Molecular cloning, characterization and expression. Mol Gen Genet 219: 106-112 (1989).

2. Bouchez D, Tokuhisa JG, Llewellyn DJ, Dennis ES, Ellis JG: The ocs-element is a component of the promoters of several T-DNA and plant viral genes. EMBO J 8: 41974204 (1989).

3. Brinkmann H, Martinez P, Quigley F, Martin W, Cerff R: Endosymbiotic origin and codon bias of the nuclear gene for chloroplast glyceraldehyde 3-phosphate dehydrogenase from maize. J Mol Evol 26: 320-328 (1987).

4. Bruhat A, Tourmente S, Chapel S, Sobrier ML, Couderc $\mathrm{JL}$, Dastugue B: Regulatory elements in the first intron contribute to transcriptional regulation of $\beta 3$ tubulin gene by 20 -hydroxyecdysone in Drosophila Kc cells. Nucl Acids Res 18: 2861-2867 (1990).

5. Callis J, Fromm M, Walbot V: Introns increase gene expression in cultured maize cells. Genes Devel 1: 11831200 (1987).

6. Chung S, Perry R: Importance of introns for expression of mouse ribosomal protein gene rpL32. Mol Cell Biol 9: 2075-2082 (1989).

7. Chupeau Y, Bourgin JP, Missonier C, Dorion N, Morel G: Préparation et culture de protoplastes de divers Nicotiana. CR Acad Sci 278: 1565-1568 (1974).

8. Curie C, Liboz T, Bardet C, Gander E, Médale C, Axelos M. Lescure B: Cis and trans-acting elements involved in the activation of Arabidopsis thaliana Al gene encoding the translation elongation factor EF- $1 \alpha$. Nucl Acids Res 19: $1305-1310$ (1991).

9. Fromm M, Taylor LP, Walbot V: Expression of genes transferred into monocot and dicot plant cells by electroporation. Proc Natl Acad Sci USA 82: 5824-5828 (1985).

10. Giuliano G, Pichersky E, Malik VS, Timko MP, Scolnik PA, Cashmore AR: An evolutionarily conserved protein binding sequence upstream of a plant light-regulated gene. Proc Natl Acad Sci USA 85: 7089-7093 (1988).

11. Goodall GJ, Filipowicz W: Different effects of intron nucleotide composition and secondary structure on premRNA splicing in monocot and dicot plants. EMBO J 10: 2635-2644 (1991).

12. Green PJ, Kay SA, Chua N-H: Sequence-specific interactions of a pea nuclear factor with light-responsive elements upstream of the rbcS-3A gene. EMBO J 6: $2543-$ 2549 (1987).
13. Gruissem W: Of fingers, zippers, and boxes. Plant Cell 2: 827-828 (1990).

14. Hovemann B, Richter S, Waldorf U, Cziepluch C: Two genes encode related cytoplasmic elongation factors (EF$1 \alpha)$ in Drosophila melanogaster with continuous and stage specific expression. Nucl Acids Res 16: 3175-3193 (1988).

15. Huet J, Sentenac A: TUF, the yeast DNA-binding factor specific for UAS rpg upstream activating sequences: Identification of the protein and its DNAbinding domain. Proc Natl Acad Sci USA 84: 3648-3652 (1987).

16. Jefferson RA, Kavanagh TA, Bevan MW: GUS fusions: $\beta$-glucuronidase as a sensitive and versatile gene fusion marker in higher plants. EMBO J 6: 3901-3907 (1987).

17. Keith B, Chua N-H: Monocot and dicot pre-mRNAs are processed with different efficiencies in transgenic tobacco. EMBO J 5: 2419-2425 (1986).

18. Lendstra JA, Van Vliet A, Arnberg AC, Van Hemert FJ, Moller W: Genes coding for the elongation factor EF- $1 \alpha$ in Artemia. Eur J Biochem 155: 475-483 (1986).

19. Liboz T, Bardet C, Le Van Thai A, Axelos M, Lescure $B$ : The four members of the gene family encoding the Arabidopsis thaliana translation factor EF- $1 \alpha$ are actively transcribed. Plant Mol Biol 14: 107-110 (1989).

20. Monaci P, Nicosia A, Cortese R: Two different liverspecific factors stimulate in vitro transcription from the human $\alpha$ 1-antitrypsin promoter. EMBO J 7: 2075-2087 (1988).

21. Pfeifer K, Arcangioli B, Guarente L: Yeast HAP1 activator competes with the factor $\mathrm{RC} 2$ for binding to the upstream activation site UAS1 of $C Y C 1$ gene. Cel 49 : 9-18 (1987).

22. Pröls M, Töpfer R, Schell J, Steinbiss H-H: Transient gene expression in tobacco protoplasts. I. Time course of CAT appearance. Plant Cell Rep 7: 221-224 (1988).

23. Riis B, Rattan SIS, Clark BFC, Merrick WC: Eukaryotic protein elongation factors. Trends Biochem Sci 15: 420424 (1991).

24. Ripe RA, Lorenzen SI, Brenner DA, Breindl M: Regulatory elements in $5^{\prime}$ flanking region and the first intron contribute to transcriptional control of the mouse alpha 1 type collagen gene. Mol Cell Biol 9: 2224-2227 (1989).

25. Shewmaker CK, Ridge NP, Pokalsky AR, Rose RE, Hiatt WR: Nucleotide sequence of an EF- $1 \alpha$ genomic clone from tomato. Nucl Acids Res 18: 4276 (1990).

26. Singh K, Dennis ES, Ellis JG, Llewellyn DJ, Tokuhisa JG, Wahleithner JA, Peacock WJ: OCSBF-1, a maize ocs enhancer binding factor: isolation and expression during development. Plant Cell 2: 891-903 (1990).

27. Uetsuki T, Naito A, Nagata S, Kaziro Y: Isolation and characterization of the human chromosomal gene for polypeptide chain elongation factor EF-1 $\alpha$. J. Biol Chem 264: 5791-5798 (1989).

28. Willmitzer L: The use of transgenic plants to study plant gene expression. Trends Genet 4: 13-18 (1988). 